\title{
Current Evidence in Management of Concussion Baseline Testing in ADHD and Learning Difficulties Patients: A Critically Appraised Topic
}

\author{
Mindi Fisher, DAT, LAT, ATC, ITAT, ${ }^{1}$ Ryan Tierney, PhD, LAT, ATC, ${ }^{2}$ \\ Anne Russ, PhD, LAT, ATC, ${ }^{2}$ and Jamie Mansell, PhD, LAT, ATC ${ }^{2}$ \\ ${ }^{1}$ California University of Pennsylvania; ${ }^{2}$ Temple University
}

\begin{abstract}
Clinical Question: In concussed patients, will having attention deficit hyperactivity disorder (ADHD) or learning difficulties (LD) versus not having ADHD or LD cause higher symptom severity scores or invalid baseline protocols? Clinical Bottom Line: Research supports the concept that there is a difference at baseline for individuals with ADHD and/or LD compared with those who do not.
\end{abstract}

Keywords: adolescent, clinical evaluation, functional performance, neurophysiology

Attention deficit hyperactivity disorder (ADHD) and other learning difficulties (LD) are neurocognitive disorders that can occur individually or concurrently. ${ }^{1}$ Those who suffer from LD commonly experience dyslexia or dyscalculia. ${ }^{1,2} \mathrm{ADHD}$ has a prevalence rate of $5.3 \%$ worldwide and is the most commonly occurring neurobehavioral childhood disorder. ${ }^{2}$ These individuals often demonstrate inattention and/or overactivity-impulsiveness in all environments of life. ${ }^{1,3}$

ADHD and LD have symptoms which keep individuals from set-shifting, planning, working memory, and verbal fluency, as well as similar symptoms of a concussion without having an injury. ${ }^{1}$ Additionally, patients with the diagnosis of ADHD have been found to have increased history of concussions. ${ }^{4}$ Based on similarities, it can be difficult to baseline test and evaluate for a concussion. Invalid baseline scores can occur when someone tries to obtain low results or has a condition such as ADHD or LD. It is important that additional research is conducted to better understand what is considered a valid protocol when baseline testing individuals with ADHD and/or LD. This Critically Appraised Topic (CAT) serves to review the current evidence regarding appropriate composite scores and normal symptoms and/or severity scores when assessing concussions at baseline and follow-up in patients diagnosed with ADHD and/or LD. Results can be used to help clinicians make an informed decision whether to retest at baseline or what should be considered "normal" in this patient population.

\section{Focused Clinical Question}

In concussed patients, will having ADHD or LD versus not having ADHD or LD cause higher symptom severity scores or invalid baseline protocols?

\section{Search Strategy}

A database search was conducted in July 2018 through Ovid, PubMed, and Medline. The search terms used were:

Fisher is with California University of Pennsylvania, California, PA. Tierney, Russ, and Mansell are with Temple University, Philadelphia, PA.

Fisher (mindi.dauria@gmail.com) is corresponding author.
- Patient: concussion, mild traumatic brain injury, mTBI

- Intervention: ADHD, attention deficit hyperactivity disorder, learning difficulties or disabilities, academic difficulties, dyslexia, dysgraphia, dyscalculia

- Outcome: Severity score, symptom score, invalid protocol

\section{Inclusion Criteria}

- Studies that identify ADHD and/or learning difficulties as associated with concussion or mild traumatic brain injury (mTBI)

- Studies that identify symptoms, symptoms severity, or invalid protocol when baseline testing for concussion in ADHD and/or LD population

- Retrospective, cross-sectional studies

- Full-text and in English

\section{Exclusion Criteria}

- Studies that used methods other than graded symptom checklist (GSC), standardized assessment of concussion (SAC), or neurocognitive testing (ImPACT specifically)

- Studies published outside of 2007 through the present

- Case studies

\section{Evidence Quality Assessment}

Each study included was evaluated use the PEDro scale or STROBE statement (Tables 1 and 2). Two scales were used due to differences in types of studies found to support the clinical question.

\section{Results of Search}

Initial searches found 21 articles to assess for inclusion or exclusion. The search of the literature then yielded 9 studies for possible inclusion. A total of three cross-sectional studies and three retrospective cohort studies met the inclusion criteria. 
Table 1 Included Studies

\begin{tabular}{|c|c|c|c|}
\hline & Iverson et al. ${ }^{3}$ & Manderino \& Gunstand 5 & Collings et al. ${ }^{6}$ \\
\hline Study Title & $\begin{array}{l}\text { High School Athletes with } \\
\text { ADHD and Learning Difficulties } \\
\text { Have a Greater Lifetime } \\
\text { Concussion History }\end{array}$ & $\begin{array}{l}\text { Collegiate Student Athletes with } \\
\text { History of ADHD or Academic } \\
\text { Difficulties Are More Likely to } \\
\text { Produce an Invalid Protocol on } \\
\text { Baseline ImPACT Testing }\end{array}$ & $\begin{array}{l}\text { Attention-Deficit/ Hyperactivity } \\
\text { Disorder is Associated with } \\
\text { Baseline Child Sport Concussion } \\
\text { Assessment Tool Third Edition } \\
\text { Scores in Hockey Players }\end{array}$ \\
\hline Study Participants & $\begin{array}{l}32,487 \text { adolescent student athletes } \\
\text { aged } 13-18 \text { years; average age }= \\
15.5 \text { years; } 17,582 \text { boys and } \\
14,905 \text { girls grouped into four } \\
\text { categories: (1) ADHD group }= \\
1,324,(2) \text { ADHD and LD } \\
\text { group }=728,(3) \text { LD group }= \\
2,710,(4) \text { no ADHD or LD } \\
\text { group }=27,705 \text {; all participants } \\
\text { completed preseason ImPACT } \\
\text { baseline testing. }\end{array}$ & $\begin{array}{l}949 \text { NCAA Division I student- } \\
\text { athletes; average age = } \\
19.47 \text { years; all participants } \\
\text { completed preseason ImPACT } \\
\text { baseline testing; data grouped into } \\
\text { ADHD, academic difficulties, } \\
\text { comorbid ADHD/academic } \\
\text { difficulties. }\end{array}$ & $\begin{array}{l}304 \text { boys ages } 8-12 \text { years; aver- } \\
\text { age age }=10.2 \text { years; all subjects } \\
\text { were members of a regional } \\
\text { hockey association in British } \\
\text { Columbia. }\end{array}$ \\
\hline Inclusion/ Exclusion Criteria & $\begin{array}{l}\text { No exclusion from taking } \\
\text { ImPACT baseline. Exclusion of } \\
\text { data if participant did not com- } \\
\text { plete history fully or history of } \\
\text { epilepsy, meningitis, and/or } \\
\text { history of brain surgery. }\end{array}$ & $\begin{array}{l}\text { Exclusion if relevant demo- } \\
\text { graphic and history questions } \\
\text { were not completed. }\end{array}$ & $\begin{array}{l}\text { Members of the hockey associa- } \\
\text { tion seen for baseline testing at a } \\
\text { registered athletic therapy clinic. } \\
\text { Exclusion if missing health his- } \\
\text { tory information or had a history } \\
\text { of learning disorder or epilepsy. }\end{array}$ \\
\hline Outcome Measures & $\begin{array}{l}\text { Computerize measure of symp- } \\
\text { toms, symptom rating, and } \\
\text { cognitive function intended for } \\
\text { concussions was completed using } \\
\text { the ImPACT testing battery. }\end{array}$ & $\begin{array}{l}\text { ImPACT composite scores } \\
\text { (verbal memory, visual memory, } \\
\text { visual-motor speed, reaction time, } \\
\text { and impulse control) and protocol } \\
\text { validity. }\end{array}$ & $\begin{array}{l}\text { Completion of Child-SCAT3 to } \\
\text { assess symptom rating, physical } \\
\text { assessment, cognitive demo- } \\
\text { graphics, and health history. Next } \\
\text { SAC-C to assess orientation, } \\
\text { immediate memory, concentra- } \\
\text { tion, and delayed recall. Lastly, } \\
\text { completion of the Balance Error } \\
\text { Scoring System (BESS) to assess } \\
\text { balance in single-, double-, and } \\
\text { tandem-stance with coordination. }\end{array}$ \\
\hline Results & $\begin{array}{l}\text { Athletes with ADHD, LD, or } \\
\text { ADHD and LD reported a higher } \\
\text { number of prior concussions } \\
(p<.05) \text {. }\end{array}$ & $\begin{array}{l}\text { Student athletes with academic } \\
\text { difficulties and comorbid ADHD/ } \\
\text { academic difficulties performed } \\
\text { worse on the ImPACT composite } \\
\text { scores (Pillai's Trace }=0.05 \text { ). } \\
\text { Student athletes with comorbid } \\
\text { difficulties had higher invalid } \\
\text { protocols ( } 10.5 \% \text { invalid, } \\
p=.004) \text {. Student athletes with } \\
\text { ADHD were more likely to pro- } \\
\text { duce invalid protocols than those } \\
\text { without }(7.7 \% \text { compared to } 2.6 \% \\
\text { invalid, } p=.005) \text {. }\end{array}$ & $\begin{array}{l}\text { Children with ADHD had sig- } \\
\text { nificantly more symptoms } \\
(\mathrm{d}=0.95) \text { and increased symptom } \\
\text { severity }(\mathrm{d}=1.13) \text { compared to } \\
\text { those with no ADHD. No statis- } \\
\text { tical differences between ADHD } \\
\text { and no ADHD when comparing } \\
\text { Child-SCAT3 measures of cog- } \\
\text { nitive or physical functioning. }\end{array}$ \\
\hline Level of Evidence & 4 & $3 b$ & 4 \\
\hline Score & STROBE $4 / 5$ & PEDro 14/22 & PEDro $14 / 22$ \\
\hline Support for the Answer? & No & No & Yes \\
\hline
\end{tabular}

Abbreviations: $\mathrm{ADHD}=$ attention deficit hyperactivity disorder; Child-SCAT3 = Sport Concussion Assessment Tool, 3rd Edition for Children; ImPACT = Immediate Post-Concussion Assessment and Cognitive Testing; $\mathrm{LD}=$ learning difficulties; SAC-C = Standardized Assessment of Concussion - Child Version.

\section{Results of Evidence Quality Assessment}

Six studies were selected for inclusion, completed as preseason baseline testing for various athletic populations, and did not focus on those with ADHD or LD. The author evaluated each study using the PEDro or STROBE scale. Three cross-sectional studies ${ }^{5,6,7}$ received a 14/22 using the PEDro scale. The cohort studies assessed with the STROBE scale had the following results: Iverson et al. ${ }^{3}=4 / 5$, Cook et al. ${ }^{8}=4 / 5$, and Biederman et al. ${ }^{4}=5 / 5$. All reviewed studies completed baseline testing, followed by data review by an examiner to ensure that all relevant health and medical history were completed, and no previous history of epilepsy, brain surgery, or seizure disorders were occurring. Studies included in this review then organized patients into groups as controls with no ADHD or LD, ADHD, LD, and ADHD and LD. There was no follow-up information done with the subjects or needed for the 
Table 2 Included Studies

\begin{tabular}{|c|c|c|c|}
\hline & Nelson et al. ${ }^{7}$ & Cook et al. ${ }^{8}$ & Biederman et al. ${ }^{4}$ \\
\hline Study Title & $\begin{array}{l}\text { Multiple Self-Reported Concus- } \\
\text { sions are More Prevalent in } \\
\text { Athletes with ADHD and } \\
\text { Learning Disability }\end{array}$ & $\begin{array}{l}\text { Baseline Cognitive Test Per- } \\
\text { formance and Concussion-like } \\
\text { Symptoms Among Adoles- } \\
\text { cent Athletes with ADHD: } \\
\text { Examining Differences Based } \\
\text { on Medication Use }\end{array}$ & $\begin{array}{l}\text { Mild Traumatic Brain Injury and } \\
\text { Attention-Deficit Hyperactivity } \\
\text { Disorder in Young Student } \\
\text { Athletes }\end{array}$ \\
\hline Study Participants & $\begin{array}{l}\text { 4,238 male football players from } \\
15 \text { US colleges from 1999-2001; } \\
3,961 \text { high school student athletes } \\
\text { from southeastern Wisconsin } \\
\text { participating in football, hockey, } \\
\text { and boys' and girls' soccer; } 8,056 \\
\text { used for sample based on identi- } \\
\text { fication of ADHD or learning } \\
\text { disability history; average } \\
\text { age }=18 \text { years. }\end{array}$ & $\begin{array}{l}39,247 \text { adolescent athletes } \\
\text { between the ages of } 13-18 \text {; } \\
\text { average age }=15.5 \text { years. }\end{array}$ & $\begin{array}{l}29 \text { student athletes between the } \\
\text { ages of } 12-25 \text { years who had } \\
\text { sustained a mTBI in the previous } \\
10 \text { years. }\end{array}$ \\
\hline Inclusion/ Exclusion Criteria & $\begin{array}{l}\text { Must be athletes at the partici- } \\
\text { pating institutions and participat- } \\
\text { ing in the identified sports. }\end{array}$ & $\begin{array}{l}\text { Exclusion if subject suffered a } \\
\text { concussion in prior } 6 \text { months } \\
\text { or had a history of epilepsy, } \\
\text { brain surgery, or meningitis. }\end{array}$ & $\begin{array}{l}\text { Exclusion of subjects with post- } \\
\text { concussive neurological sequelae } \\
\text { such as seizures or severe/fre- } \\
\text { quent headaches in the past } \\
\text { month; subjects with psychiatric } \\
\text { disorder requiring hospitalization, } \\
\text { diagnosis of autism, psychosis, } \\
\text { bipolar disorder, or epilepsy. }\end{array}$ \\
\hline Outcome Measures & $\begin{array}{l}\text { Demographic, health history, } \\
\text { symptoms, and cognitive perfor- } \\
\text { mance measured through one-on- } \\
\text { one interviews, graded symptom } \\
\text { checklist, standardized assess- } \\
\text { ment of concussion, and neuro- } \\
\text { logical measures. }\end{array}$ & $\begin{array}{l}\text { Baseline ImPACT testing } \\
\text { prior to participating in a sport } \\
\text { to assess cognitive function, } \\
\text { postconcussion symptom } \\
\text { scale, and health history. }\end{array}$ & $\begin{array}{l}\text { 2-hr assessment battery to collect } \\
\text { medical and psychiatric history } \\
\text { about head injury and ADHD } \\
\text { symptoms (Behavior Rating } \\
\text { Inventory of Executive Function). } \\
\text { Additionally, the British Colum- } \\
\text { bia Post-Concussion Symptom } \\
\text { Inventory and ImPACT were } \\
\text { completed. }\end{array}$ \\
\hline Results & $\begin{array}{l}\text { ADHD and LD were associated } \\
\text { with } 2.93 \text { and } 2.08 \text { higher prev- } \\
\text { alence of } 3+\text { concussions. ADHD } \\
\text { reported more baseline symptoms } \\
(5.76 \text { vs. } 3.05, p<.001) \text { and } \\
\text { poorer performance on baseline } \\
\text { cognitive test. }\end{array}$ & $\begin{array}{l}\text { Girls with ADHD and not } \\
\text { taking medication had mod- } \\
\text { estly great rates of invalid } \\
\text { scores compared to controls } \\
(5.2 \%, \mathrm{OR}=2.21,95 \% \mathrm{CI}= \\
1.92-2.50) \text {. ADHD with and } \\
\text { without medicine had little } \\
\text { difference in symptom score } \\
\text { but greater difference from } \\
\text { those without ADHD. }\end{array}$ & $\begin{array}{l}\text { mTBI subjects had significantly } \\
\text { higher rate of ADHD than con- } \\
\text { trols without } \mathrm{mTBI}(31 \% \text { vs. } 9 \% \text {, } \\
p<.012) . \text { mTBI }+ \text { ADHD had } \\
\text { higher fatigue ( } 3.4 \text { vs. } 1.9, \\
p=.029) \text { and poor concentration } \\
(4.0 \text { vs. } 1.9, p=.008) \text { than those } \\
\text { with mTBI - ADHD. }\end{array}$ \\
\hline Level of Evidence & 4 & 4 & 4 \\
\hline Score & PEDro $14 / 22$ & STROBE $4 / 5$ & STROBE $5 / 5$ \\
\hline Support for the Answer? & Yes & Yes & Yes \\
\hline
\end{tabular}

Abbreviations: $\mathrm{ADHD}=$ attention deficit hyperactivity disorder; ImPACT = Immediate Post-Concussion Assessment and Cognitive Testing; LD = learning difficulties; $\mathrm{mTBI}=$ mild traumatic brain injury .

research related to this area. Unfortunately, none of the studies completed follow-up after baseline with patients who experience ADHD and/or LD to determine if results were valid unless they had suffered from a concussion, and comparisons were then made to the control groups.

\section{Clinical Bottom Line}

The research supports the concept that there is a difference at baseline for individuals with ADHD and/or LD compared with those without. Evidence shows that individuals with these conditions often experience higher symptom severity scores, specifically in the areas of fatigue, difficulty remembering, difficulty concentrating, trouble sleeping, and balance problems. Often, individuals with ADHD will have an invalid protocol baseline on the ImPACT. Invalid protocols occur when the composite scores are lower than the normal scores for the related population at optimal cognitive function. ${ }^{8}$ This indicates that the ADHD and/ or LD populations may require different normal protocols to compare against when they are injured. According to the Strength of Recommendation Taxonomy (SORT), there is level B evidence to support the need for understanding of appropriate baseline 
values for individuals with ADHD and/or LD when they sustain a concussion. The recommendation of level $\mathrm{B}$ was chosen because most of the studies had limited patient-oriented evidence and were level 4 studies according to the Centre for Evidence-Based Medicine (CEBM) guidelines. Defined symptoms and understanding of invalid composite scores are necessary for treating healthcare providers to properly identify and treat individuals ADHD and/or LD who are being treated under their care.

\section{Implications for Practice}

There is evidence to suggest that students with ADHD and/or LD have a greater history of prior concussions and may be predisposed for concussions due to their condition. ${ }^{3,4}$ When assessing baseline scores using ImPACT as a neurocognitive battery, the composite scores in verbal memory and visual-motor speed are significantly lower in individuals with both ADHD and LD. 5,7,8 Symptoms that have a higher frequency and severity level that are associated with ADHD and LD at baseline are fatigue, difficulty remembering, difficulty concentrating, trouble sleeping, and balance problems.

In studies completed by Iverson et al. ${ }^{3}$ and Biederman et al., ${ }^{4}$ ADHD and LD were found to be a predisposing factor for concussions. Additionally, these individuals often have a history of one or more concussions compared to those who do not have either condition. Iverson et al. found that the self-reported rate of at least one concussion in ADHD subjects is $24.5 \%(p<.001, \mathrm{OR}=1.69$, $95 \% \mathrm{CI}=1.48-1.93)$, ADHD and LD is $25.8 \%(p<.0001, \mathrm{OR}=$ $1.81,95 \% \mathrm{CI}=1.52-2.14)$, or academic difficulties but not diagnosed ADHD is $19.7 \%(p<.0001, \mathrm{OR}=1.27,95 \% \mathrm{CI}=1.15-$ $141) .{ }^{3}$ Due to the increased nature of impulsivity and dysfunction in individuals with ADHD and LD, there is an increased risk of injuries, including those to the head which may result in concussions. In the Bierderman et al. study, those with ADHD had a greater percentage of subjects with one or more head injuries than the controls (57.1 vs. $30.8, p=.4) .{ }^{4}$ Based on the results of these two studies, clinicians working with patients who have been diagnosed with ADHD or LD should pay attention to the number of previous concussions reported and motion activity, and ensure proper mechanics to help decrease the occurrence of additional concussions.

When using the SAC, GSC, and symptom report from ImPACT, Bierderman et al., Nelson et al., and Collings et al. all found similar symptoms reported at an increased amount in individuals with ADHD and/or LD. ${ }^{4,6,7}$ Bierderman et al. found that fatigue (3.4 vs. $1.9, p=.029)$ and poor concentration (4.0 vs. $1.9, p=.008)$ were more significantly severe in those with ADHD and/or LD than the controls. ${ }^{4}$ When Collings et al. compared number of symptoms between the comorbid groups and controls, they found that the mean was 8.02 vs. 12.50 , with a severity score of 11.42 vs. $20.80 .^{6}$ This particular study found headaches, dizziness, and feeling faint occurred at a higher rate than normal for ADHD and LD patients. Lastly, Nelson et al. used the GSC to compare ADHD and LD to controls' symptoms. The mean symptom rating in the ADHD group was 5.76 versus the control mean of $3.05, p<.001 .^{7}$ They found the ADHD-only group reported the following symptoms: fatigue $(31 \%$ vs. $10 \%, p<.001)$, trouble sleeping $(25 \%$ vs. $13 \%, p<.001)$, difficulty remembering $(21 \%$ vs. $8 \%, p<.001)$, balance problems $(14 \%$ vs. $7 \%, p=.003)$, and feeling in a "fog" (6\% vs. $3 \%, p=.034)$. Patients who experience ADHD or LD should have a baseline symptom score unassociated with concussions. This information will allow clinicians to better understand what symptoms they commonly experience and what would be considered out of the ordinary or accentuated.

The ImPACT test battery is often used a baseline measure for athletes of various ages to assess medical history and composite scores in four areas. Biederman et al., Nelson et al., and Cook et al. looked at invalid protocols of ImPACT composite scores for individuals with ADHD and/or LD and controls., ${ }^{4,8}$ Bierderman et al. found that verbal memory (72.3 vs. 72.1$)$, visual motor speed (62.9 vs. 54.3$)$, and reaction time (60.4 vs. 44.8) composites were substantially worse in individuals with mTBI and ADHD than those with mTBI and no ADHD, but it did not attain statistical significance. ${ }^{4}$ As a useful test battery, there is information lacking about how it should be used to assess the ADHD or LD population accurately.

Comparably, Nelson et al. also found that ADHD played a role for lower baseline performance of immediate recall $(\mathrm{d}=-0.53)$ and delayed recall $(\mathrm{d}=-0.32) .{ }^{7}$ Cook et al. looked at ImPACT results and ADHD but also at the role that medication played on the scores for individuals with ADHD who did and did not have medication. ${ }^{8}$ The group with ADHD and medication did not have significant differences in any composite scores from controls. However, the ADHD and no medication and no ADHD but medication groups for boys scored lower visual memory and visual motor speed $(\mathrm{d}=.31$ and .37$)$. In the ADHD and no medication and no ADHD but medication group for girls, the visual motor speed composite was worse $(\mathrm{d}=.32$ to .42$)$. ADHD and no medication group of girls compared to the controls differed on reaction time $(\mathrm{d}=.29)$ but the no ADHD but medication group differed from controls on verbal memory $(\mathrm{d}=-.32){ }^{8}$

Based on the literature reviewed in this CAT, the suggested identification of additional symptoms associated with ADHD and/ or LD and concussion have been identified as fatigue, difficulty concentrating, difficulty remembering, lack of balance, and trouble sleeping. Symptom severity scores above 20 should not be deemed concussed at baseline and should be tracked carefully when a concussion is sustained. More education about ImPACT composite scores will need to be understood by healthcare providers to properly understand and adapt results. Research is needed to develop appropriate parameters for ADHD and/or LD individuals on the ImPACT.

\section{CAT Kill Date: September 2021}

CATs have limited life and should be revisited approximately 2 years after publication (see https://doi.org/10.1123/ijatt.2018-0093).

\section{References}

1. Huang F, Sun L, Qian Y, Liu L, Ma QG, et al. Cognitive function of children and adolescents with attention deficit hyperactivity disorder and learning difficulties: a developmental perspective. Chin Med J (Engl). 2016;129(16):1922-1928. doi:10.4103/0366-6999. 187861

2. Czamara D, Tiesler CM, Kohlbock G, et al. Children with ADHD symptoms have a higher risk for reading, spelling, and math difficulties in the GINIplus and LISAplus cohort studies. PLoS One. 2013; 8(5): e63859. PubMed ID: 23724008 doi:10.1371/journal.pone. 0063859

3. Iverson GL, Wojtowicz M, Brooks BL, et al. High school athletes with ADHD and learning difficulties have a greater lifetime concussion history [published online ahead of print July 18, 2016]. J Atten Disord. doi:10.1177/1087054716657410 
4. Biederman J, Feinberg L, Chan J, et al. Mild traumatic brain injury and attention-deficit hyperactivity disorder in young student athletes. J Nerv Ment Dis. 2015;203(11):813-819. PubMed ID: 26461480 doi:10.1097/NMD.0000000000000375

5. Manderino L, Gunstand J. Collegiate student athletes with history of ADHD or academic difficulties are more likely to produce an invalid protocol on baseline ImPACT testing. Clin J Sport Med. 2018;28(2): 111-116. PubMed ID: 28731886

6. Collings LJ, Cook NE, Porter S, et al. Attention-deficit/ hyperactivity disorder is associated with baseline child sport concussion assessment tool third edition scores in child hockey players. Brain Inj. 2017;
31(11):1479-1485. PubMed ID: 28980829 doi:10.1080/02699052. 2017.1377351

7. Nelson LD, Guskiewicz KM, Marshall SW, et al. Multiple selfreported concussions are more prevalent in athletes with ADHD and learning disability. Clin J Sport Med. 2016;26(2):120-127. PubMed ID: 25915144 doi:10.1097/JSM.0000000000000207

8. Cook NE, Huang DS, Silverberg N, Brooks BL, Maxwell B. Baseline cognitive test performance and concussion-like symptoms among adolescent athletes with ADHD: examining differences based on medication use. Clin Neuropsychol. 2017;31(8):1341-1352. PubMed ID: 28429656 doi:10.1080/13854046.2017.1317031 